\title{
ICRF Wall Conditioning: Present Status and Developments for Future Superconducting Fusion Machines
}

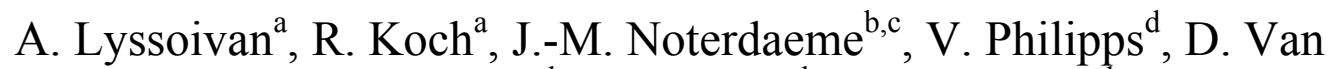
Eester $^{\mathrm{a}}$, M. Vervier ${ }^{\mathrm{a}}$, V. Rohde ${ }^{\mathrm{b}}$, V. Bobkov ${ }^{\mathrm{b}}$, G. Sergienko $^{\mathrm{d}}$, E. de la Cal ${ }^{\mathrm{e}}$, H.G. Esser ${ }^{\mathrm{d}}$, E. Gauthier ${ }^{\mathrm{f}}$, D.A. Hartmann ${ }^{\mathrm{b}}$, D. Douai ${ }^{\mathrm{f}}$, F. Louche ${ }^{\mathrm{a}}$, N. Ashikawa ${ }^{g}$, Y.D. Bae ${ }^{\mathrm{h}}$, B. Beaumont ${ }^{\mathrm{i}}$, A. Becoulet ${ }^{\mathrm{f}}, \mathrm{S}$. Bremond ${ }^{\mathrm{f}}$, R. Dumont ${ }^{\mathrm{f}}, \mathrm{M}$. Graham ${ }^{\mathrm{j}}$, J. Hu ${ }^{\mathrm{k}}$, J.G. Kwak ${ }^{\mathrm{h}}$, R. Laengner ${ }^{\mathrm{d}}$, P.U. Lamalle ${ }^{\mathrm{i}}$, E. Lerche ${ }^{\mathrm{a}}$, O. Marchuk ${ }^{\mathrm{d}}$, M.-L. Mayoral ${ }^{\mathrm{j}}$, V.E. Moiseenko, I. Monakhov ${ }^{\mathrm{j}}$, M. Nightingale ${ }^{\mathrm{j}}$, J. Ongena ${ }^{\mathrm{a}}$, M.K. Paul ${ }^{\mathrm{a}}$, R. Pitts ${ }^{\mathrm{i}}$, V. Plyusnin ${ }^{\mathrm{m}}$, O. Schmitz, F.C. Schüller ${ }^{\mathrm{i}}$, M. Shimada, B. Unterberg ${ }^{\mathrm{d}}$, M. Van Schoor ${ }^{\mathrm{a}}$, G. Van Wassenhove ${ }^{\mathrm{a}}$, E.D. Volkov, T. Wauters ${ }^{\mathrm{f}}$, R. Weynants ${ }^{\mathrm{a}}$, Y. Zhao ${ }^{\mathrm{k}}$, the TEXTOR Team, the TORE SUPRA Team, the ASDEX Upgrade Team, JET EFDA Contributors*, the URAGAN-2M Team, the LHD Team, the EAST Team and the KSTAR Team

${ }^{a}$ Laboratory for Plasma Physics-ERM/KMS, Association Euratom-Belgian State, 1000 Brussels, Belgium**

${ }^{b}$ Max-Planck Institut für Plasmaphysik, Euratom Association, 85748 Garching, Germany ${ }^{c}$ Gent University, EESA Department, B-9000 Gent, Belgium

${ }^{d}$ Institut für Energieforschung-Plasmaphysik FZ Jülich, Euratom Association, 52425 Jülich, Germany**

${ }^{e}$ Laboratorio Nacional de Fusión, Association Euratom-CIEMAT, 28040 Madrid, Spain

${ }^{f}$ CEA, IRFM, Association Euratom-CEA, 13108 St Paul lez Durance, France

${ }^{g}$ National Institute for Fusion Science, 322-6 Oroshi-cho, Toki, Gifu 509-5292, Japan

${ }^{h}$ FEC KAERI, 1045 Daedeokdaero Yuseong Daejeon 305-353, Korea

${ }^{i}$ ITER International Organization, F-13067 St Paul lez Durance, France

${ }^{j}$ UKAEA/Euratom Fusion Association, Culham Science Centre, OX14 3DB, Abingdon, United Kingdom ${ }^{k}$ Institiute of Plasma Physics,CAS, 230031 Hefei, P.R.China

Institute of Plasma Physics, National Science Centre KIPT, 61108 Kharkov, Ukraine

${ }^{m}$ Instituto de Plasmas e Fusao Nuclear Associacao EURATOM-IST 1049-001 Lisbon, Portugal

* See the Appendix of F. Romanelli et al., Fusion Energy Conference 2008 (Proc. 22nd Int. FEC Geneva, 2008) IAEA (2008)

**Partners in the Trilateral Euregio Cluster (TEC)

\begin{abstract}
ITER and future superconducting fusion machines need efficient wall conditioning techniques for routine operation in between shots in the presence of permanent high magnetic field for wall cleaning, surface isotope exchange and to control the in-vessel long term tritium retention. Ion Cyclotron Wall Conditioning (ICWC) based on the ICRF discharge is fully compatible and needs the presence of the magnetic field. The present paper focuses on the
\end{abstract}


principal aspects of the ICWC discharge performance in large-size fusion machines: (i) neutral gas RF breakdown with conventional ICRF heating antennas, (ii) antenna coupling with low density $\left(\sim 10^{17} \mathrm{~m}^{-3}\right)$ RF plasmas and (iii) ICWC scenarios with improved RF plasma homogeneity in the radial and poloidal directions. All these factors were identified as crucial to achieve an enhanced conditioning effect (e.g. removal rates of selected "marker" masses). All the observed effects are analyzed in terms of RF plasma wave excitation/absorption and compared with the predictions from 1-D RF full wave and 0-D RF plasma codes. Numerical modeling and empirical extrapolation from the existing machines give good evidence for the feasibility of using ICWC in ITER with the main ICRF antenna.

Keywords: ICRF Antennas, ICRF discharge, Tokamaks/Stellarators, Toroidal/Poloidal Magnetic Fields, Wall Conditioning, ITER.

PACS: 52.20.-j, 52.25.Jm, 52.35.Fp, 52.35.Hr, 52.35.Mw, 52.40.Fd, 52.40.Hf, 52.50.Dg, 52.50.Qt, 52.55.Fa, 52.65.-y, 52.70.-m, 52.80.Pi, 52.80.-s.

\section{INTRODUCTION}

The plasma production technique based on absorption of radio-frequency power in the Ion Cyclotron Range of Frequencies (ICRF) is becoming an indispensable tool for present and next generation superconducting fusion devices because of its high potential for solving several basic problems of reactor oriented machines [1]:

1. Wall conditioning (tritium retention, surface isotope exchange, wall cleaning/coating) with ICRF plasmas in the presence of permanent high magnetic field in tokamaks and stellarators.

2. Assistance with the ICRF pre-ionization for the tokamak start-up at low inductive electric field $\left(E_{0} \approx 0.3 \mathrm{~V} / \mathrm{m}\right.$ in ITER).

3. Target dense RF plasma production $\left(n_{\mathrm{e}} \geq 10^{19} \mathrm{~m}^{-3}\right)$ in stellarators.

The alternative ICRF plasma production technique was developed originally for routine use in stellarators in the scenario 3 [2] and $\mathbf{1}$ [3] and successfully adapted later for the tokamak applications in the scenario 1 [4-7] and 2 [4,8]. The present-day and future superconducting fusion machines need alternative and efficient wall conditioning techniques for the routine operation in the presence of permanent high magnetic field, which prevents the use of conventional Glow Discharge Conditioning (GDC). Ion Cyclotron Wall Conditioning (ICWC) discharge is fully compatible with the presence of the magnetic field. Given this feature and the encouraging conditioning/cleaning results recently achieved on the present-day tokamaks and stellarators (summarized in Refs. [4-7, 9-16]), ICWC was recently confirmed as a functional requirement on the ITER ICRF heating and current drive system [17]. Therefore, further development of the ITER relevant ICWC scenarios with conventional ICRF antennas is an important and urgent task.

The paper presents a review of basic principles of ICRF plasma production with standard ICRF antennas and its application for the ICWC purpose. The concept of ICRF plasma production based mainly on the electron collisional absorption of the RF power is described. The RF plasma parameters achieved in different ICWC scenarios $\left(n_{\mathrm{e}} \sim 10^{17} \mathrm{~m}^{-3}, T_{\mathrm{e}} \sim 2-5 \mathrm{eV}\right.$, low ionization degree $\left.\sim 1-10 \%\right)$ are characterized and compared with those predicted by the 1-D RF code TOMCAT [18] and newly developed plasma transport codes: 0-D [19] and 1-D [20]. The main ICWC results achieved in the present-day fusion machines are analyzed in terms of the removal rate for selected gas species. Finally, we discuss a perspective on the feasible applications 
of this new conditioning technique in ITER in the presence of high $B_{\mathrm{T}}=2.65-5.3 \mathrm{~T}$ using the main ICRF antenna.

\section{ICRF PLASMA PRODUCTION}

\subsection{Basic Principles of ICRF Plasma Production}

The initiation of ICRF discharge in a toroidal magnetic field $B_{\mathrm{T}}$ results from the absorption of RF energy mainly by electrons [2,4,21-22]. The RF $\widetilde{E}_{z}$-field (parallel to the $B_{\mathrm{T}}$-field) is considered to be responsible for this process. However, in the typical ICRF band $(\sim 10-100 \mathrm{MHz})$ in the present-size fusion devices, for most of the antenna $\kappa_{z}$-spectrum, the RF waves (cylindrical modes) cannot propagate in the vacuum torus: $\kappa_{\perp}^{2}=\omega^{2} / c^{2}-\kappa_{z}^{2}<0$, where $\kappa_{\perp}$ is the perpendicular wave-vector, $\omega=2 \pi f, f$ is the RF generator frequency. Hence, the neutral gas breakdown and initial ionization may only occur locally at the antenna-near $\widetilde{E}_{z}$-field (evanescent in vacuum). In the general case of the poloidal ICRF antenna with a tilted Faraday screen (FS), the RF $\widetilde{E}_{z}$-field in vacuum can be induced electrostatically and inductively [4]. The electrostatic mechanism results from the RF potential difference between the central conductor and the side parts of the antenna box (side protection RF limiters). The inductive mechanism results from the RF voltage induced between the FS rods by the timevarying magnetic flux. Simplified analytical description of the antenna-near $\widetilde{E}_{z}$-field generation in vacuum was found in a good agreement with numerical simulations done for the real antenna configurations using 3D electromagnetic codes (Fig.1).

An analysis of the parallel equation of motion for electrons in the presence of antenna-near locally generated $\widetilde{E}_{z}$-field revealed that the electrons perform complex motions: linear fast oscillations under the action of the Lorentz force and non-linear slow oscillations under the action of the $R F$ ponderomotive force [21-22]. If the oscillation energy of the electrons exceeds the ionization potential for molecules (atoms), $m_{e} v_{e z}^{2} / 2 \geq \varepsilon_{i}$, the gas ionization can proceed. However, if the amplitude of the $\mathrm{RF}$ electric field is too strong, the oscillation amplitude of electrons, $e \widetilde{E}_{z} / m_{e} \omega^{2}$, becomes comparable with or larger than the parallel length scale of the antenna $R F$ ponderomotive potential well, $L_{z}=\widetilde{E}_{z} /\left(d \widetilde{E}_{z} / d z\right)$, the electrons are expelled from the oscillated region on a time scale of the order of RF period and ionization process is hampered. Therefore, the neutral gas breakdown and initial ionization will be efficient if the electrons are trapped in the antenna RF potential wells for many periods and the amplitude of the antenna electric field meets the boundary condition:

$$
(\omega / e)\left(2 m_{e} \varepsilon_{i}\right)^{1 / 2} \leq \widetilde{E}_{z}(r) \leq m_{e} \omega^{2} L_{z} / e .
$$

As soon as a build-up of density begins to support plasma waves (this occurs at a very low density $\sim 10^{12}-10^{14} \mathrm{~m}^{-3}$ in the frequency range $10-100 \mathrm{MHz}$, when $\omega_{p e} \geq \omega$ ), the plasma waves can start exciting/propagating in a relay-race regime governed by the antenna $\kappa_{\mathrm{z}}$-spectrum, causing further space ionization of the neutral gas and plasma build-up in the torus. Because of the very low and frozen plasma temperature during the ionization phase $\left(T_{\mathrm{e}} \sim 2-5 \mathrm{eV}[5,7,13]\right)$, the RF power is expected to be dissipated mostly collisionally (random $e$-collisions with gas molecules, atoms or ions) either directly or through conversion to ion Bernstein waves (IBW) if $\omega>\omega_{c i}$ or by conversion at the Alfvén resonance (AR) if $\omega<\omega_{c i}$. Such a non-resonant coupling allows RF plasma production at any $B_{\mathrm{T}}$. 


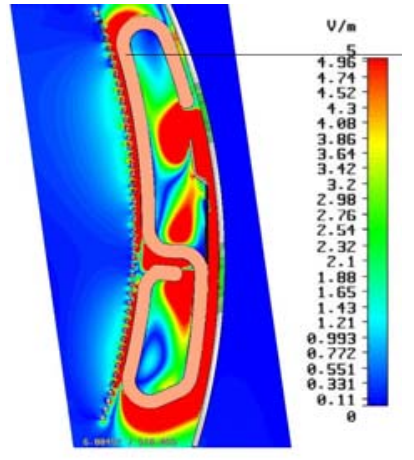

FIGURE 1. $E_{z}$-field generation by JET A-2 antenna as modeled with 3-D MWS code $(f=30 \mathrm{MHz}$, dipole-phasing for antenna straps.

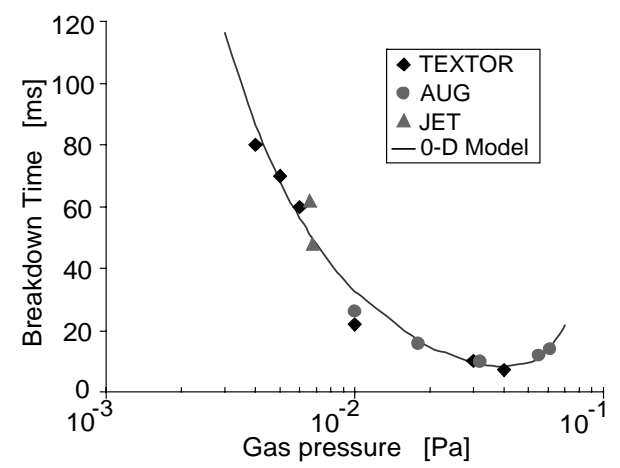

FIGURE 2. Gas breakdown time derived from the $\mathrm{H}_{\alpha}$ emission $\left(\mathrm{P}_{\mathrm{RF} / \text { strap }} \approx 30-50 \mathrm{~kW}, \mathrm{f} \approx 30\right.$ $\left.\mathrm{MHz}, \quad \omega=4 \omega_{\mathrm{cHe}^{+}}=2 \omega_{\mathrm{cHe}++}=2 \omega_{\mathrm{cD}+}=\omega_{\mathrm{cH}+}\right)$ and compared with the $0-\mathrm{D}$ model $[1,19]$.

\subsection{Neutral Gas RF Breakdown}

On applying RF voltage/power at the antenna straps, the neutral gas breakdown occurs after some time-delay characterized by the breakdown time $t_{\mathrm{bd}}$ and shows up in a drop in the antenna RF voltage and in a burst in the $H_{\alpha}$ emission $[1,13]$.

Data for the neutral gas breakdown time obtained from RF discharges with similar RF power per strap $(30-50 \mathrm{~kW})$ and frequency $(\sim 30 \mathrm{MHz})$ were found in a good agreement for three European tokamaks (TEXTOR, JET and AUG) in the measured gas pressure range (Fig.2). Further analysis of the neutral gas breakdown phase was performed using the 0-D plasma code [19], which solved numerically a set of differential particle and energy balance equations for the atoms, electrons and ions. The following atomic reactions with the updated reaction rates have been considered: electron collisional excitation and ionization of the atoms, radiative, dielectronic and three-body recombination and charge-exchange recombination. The predicted gas breakdown time, $t_{\mathrm{bd}}$, derived from the balance of the power losses between the electron ionization and the electron-ion Coulomb collisions was found in an agreement with the experimental data (Fig.2). It might be an indication that:

- Electron collisional ionization is the principal mechanism of gas ionization in the ICRF band;

- The breakdown time is independent on the machine size for the fixed RF power density (antenna $\widetilde{E}_{z}$-field);

- Plasma waves can support the plasma build-up in torus starting from the breakdown phase, since the predicted density meets already the threshold density for plasma waves excitation, $\omega_{p e} \geq \omega$.

\subsection{ICRF Antenna Coupling to Low Density RF Plasmas}

The antenna-plasma coupling efficiency is defined as a fraction of the generator power coupled by the plasma, $\eta=P_{\mathrm{RF}-\mathrm{p}} / P_{\mathrm{RF}-\mathrm{G}}[13]$. For the standard ICRH antennas in the present-day machines, this factor generally becomes rather low $\left(\eta_{0} \approx 20-30 \%\right)$ in the low-density plasma production mode $\left(n_{\mathrm{e}} \sim 10^{16}-10^{17} \mathrm{~m}^{-3}\right)$ in contrast to the scenarios of dense plasma heating $\left(\eta \geq 90 \%\right.$ at $\left.n_{\mathrm{e}}>10^{19} \mathrm{~m}^{-3}\right)$. Such difference is caused by the antenna polarization. The standard heating antenna is optimized to couple the RF power efficiently to the fast wave (FW), which propagates usually in the high- 
density plasmas only. To achieve an improved coupling $\eta$ of the standard ICRF antennas in the RF plasma production mode, several recipes have been found and successfully tested:

- Operation at high ion cyclotron harmonics, $\mathrm{HCH},\left(\omega \geq 10 \omega_{\mathrm{ci}}\right)$ by reducing $B_{\mathrm{T}}$ or increasing frequency $\left(\eta / \eta_{0} \approx 1.6-2.0\right)[13,23]$;

- $\quad$ ECRF ionization assistance for ICRF plasma production $\left(\eta_{1} / \eta_{0} \approx 1.4\right)[1,10]$;

- ICRF mode conversion (MC) in low-density RF plasmas with two ion species $\left(\eta / \eta_{0} \approx 2.0-3.0\right)[13]$

- Antenna "magnetic tilting" towards $B_{\mathrm{tot}}=B_{\mathrm{T}}+B_{\mathrm{V}}$ by superposing an additional vertical magnetic field $B_{\mathrm{V}}<<B_{\mathrm{T}}\left(\eta / \eta_{0} \approx 1.2\right)[4,23]$;

- Antenna low $k_{\mathrm{z}}$-spectrum formation by "monopole" phasing between antenna current straps $\left(\eta / \eta_{0} \approx 4.4\right)[24,25]$.

\subsection{ICRF Plasma Characterization}

Plasma density build-up and its homogeneity: The plasma production process has been studied in present-day tokamaks and stellarators under various conditions [1$15,20-23]$. The ICRF plasmas with typical density $n_{\mathrm{e}} \approx 3 \times 10^{16}-3 \times 10^{17} \mathrm{~m}^{-3}$ may reliably be produced in a wide range of machine operational parameters $\left(B_{\mathrm{T}} \approx 0.20-3.8 \mathrm{~T}\right.$, $f=25-85 \mathrm{MHz}$ in gases $\mathrm{H}_{2}, \mathrm{D}_{2}, \mathrm{He}, \mathrm{O}_{2}, \mathrm{~N}_{2}$ and their mixtures at pressures $p_{\text {tot }} \approx 10^{-3}$ $-10^{-1} \mathrm{~Pa}$ ) using standard "heating" antennas without any changes in hardware. Figure 3 shows typical RF plasma operational range in the TEXTOR tokamak. The RF plasma density showed tendency to be proportional to the injected RF power (a sign of weakly ionized plasma) and increased with the torus pressure [4]. The ionization degree was found to be rather low, $\gamma_{i}=n_{\mathrm{e}} /\left(n_{\mathrm{e}}+n_{0}\right)<0.1$, in line with the 0 -D plasma model prediction. Analysis of the exterior $\mathrm{D}_{\alpha} / \mathrm{H}_{\alpha}$ line-integrated emission measured in different sections of the torus vessel and plasma images from the top-view CCD cameras showed that ICRF plasmas were toroidally uniform [4,13]. The electron temperature (deduced from data of spectroscopic, electric probe and thermal lithium beam diagnostics) varied in the range $3-30 \mathrm{eV}$, increasing in the low gas pressure case [4] or in the presence of FW-IBW MC [13]. For the latter case, 1-D RF code predicts an enlargement of the RF power fraction absorbed by the electrons and extension of the $e$-deposited power profiles towards HFS on increasing the $\mathrm{H}^{+}$-concentration in the $\left(\mathrm{He}+\mathrm{H}_{2}\right)$-plasmas. The performance of ICWC discharges in the MC scenario at two different frequencies gave evidence for further improvement of the RF plasma homogeneity in the radial direction [13]. The additional extension of RF plasma in the vertical/radial directions was achieved by applying the poloidal magnetic field (vertical/radial, stationary/oscillating/rotating) to the toroidal one, $\mathrm{B}_{\mathrm{V}, \mathrm{R}}<<\mathrm{B}_{\mathrm{T}}[13,23]$.

Generation of High-Energy $H$ and D Atoms: A number of ICWC experiments performed until now reported on the generation of high-energetic fluxes of $H$ (with energies up to $60 \mathrm{keV}$ ) and of $D$ atoms (up to $25 \mathrm{keV}$ ) detected by a neutral particle analyzer (NPA) or Si fast neutron analyzer (FNA) in $\mathrm{D}_{2-}, \mathrm{He}-$ or $\left(\mathrm{H}_{2} / \mathrm{He}\right)$-plasmas [1,4-8]. Detailed study of the phenomenon revealed that the ion cyclotron absorption mechanism plays a fundamental role in the generation of fast ions / CX atoms:

- Intensity of the locally collected flux of CX neutrals strongly correlated with the ICR layer $\omega=\omega_{\mathrm{cH}^{+}}=2 \omega_{\mathrm{cD}+}=2 \omega_{\mathrm{cHe}^{++}}$location in the plasma cross-section $[4,13]$; 
- Heating at the first cyclotron harmonic $\left(\omega=2 \omega_{\mathrm{cH}+}\right)$ creates tail in the H-atom spectra at higher energy than fundamental heating $\left(\omega=\omega_{\mathrm{cH}^{+}}\right)$, in line with the fast particle distributions caused by RF quasilinear diffusion [13].

- Increasing the $\mathrm{H}_{2} / \mathrm{He}$-ratio (from 0 to $\approx 0.2$ ) [13] or ion cyclotron harmonic number [13-14] causes the decrease in the averaged energy of both, $\mathrm{H}$ and $\mathrm{D}$ atoms, in line with the RF power absorption modeling (Fig.4).

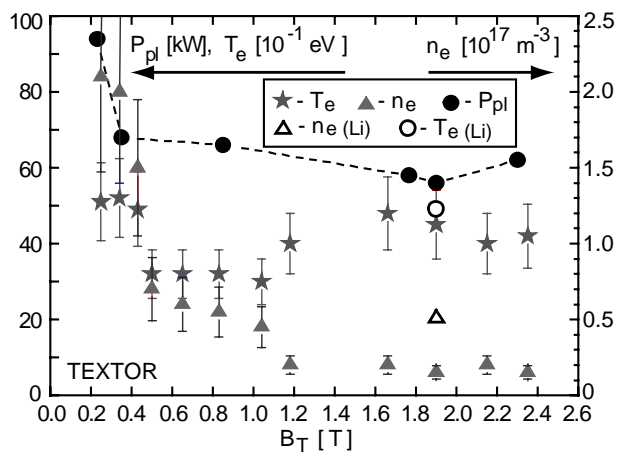

FIGURE 3. $\mathrm{B}_{\mathrm{T}}$-dependence of $n_{\mathrm{e}}, T_{\mathrm{e}}$ and coupled RF power in TEXTOR: $\mathrm{P}_{\mathrm{RF}-\mathrm{G}} \approx 120$ $\mathrm{kW}, \quad\left(\mathrm{He}+\mathrm{H}_{2}\right)$-plasma, $p_{\text {tot }} \approx(4-6) \times 10^{-2} \quad \mathrm{~Pa}$ (edge Langmuir probe at $r=0.45 \mathrm{~m}$ and thermal Li-beam data).

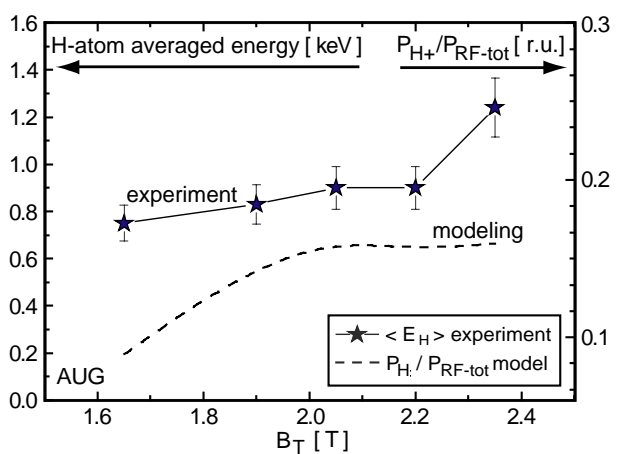

FIGURE 4. Averaged energy of hydrogen CXatoms measured by NPA in the AUG ICRF plasmas and calculated RF power absorbed by protons as function of the $\mathrm{B}_{\mathrm{T}}$-field [13].

\section{ICRF WALL CONDITIONING (ICWC)}

\subsection{ICWC in the Present-Day Machines}

The wall conditioning with low density/temperature plasmas in fusion reactor machines is aimed at wall cleaning, surface isotope exchange and tritium desorption. Generally, the conditioning effect is attributed to the removal of adsorbed gas species from the wall so that they may then be pumped out of the system. The adsorbed atoms may be removed by electronic excitation, chemical interaction and momentum/energy transfer [26]. For the latter mechanism, the desorption (removal) rate increases with the impact energy of the ions and their masses [27]. Here we define the removal rate as the quantity: $Q_{R R}(t) \sim V(d p / d t)+p \cdot s$, where $V\left(\mathrm{~m}^{3}\right)$ is the plasma volume, $p(\mathrm{~Pa})$ and $s\left(\mathrm{~m}^{3} / \mathrm{s}\right)$ are the partial pressure of the given mass and its pumping speed, respectively. Direct comparison of ICWC $\left(\omega=\omega_{\mathrm{cH}+}=4 \omega_{\mathrm{cHe}+}\right)$ and ECWC $\left(\omega=2 \omega_{\mathrm{ce}}\right)$ discharges in TEXTOR at the same conditions $\left(\mathrm{B}_{\mathrm{T}}=2.0 \mathrm{~T}\right.$, He gas at pressure $p \approx$ $2.5 \times 10^{-2} \mathrm{~Pa}$ ) revealed that the hydrogen removal rate was about 20 times higher with ICWC (Fig.5) [10]. Better homogeneity of the ICRF discharge, generation of the energetic neutrals bombarding the wall and the low electron temperature could contribute to the achieved result [12]. It should note that the homogeneity of ECWC at fundamental ECR was considerably improved by applying small horizontal magnetic field $\left(\mathrm{B}_{\mathrm{R}} / \mathrm{B}_{\mathrm{T}} \approx 2 \times 10^{-3}\right)$ [28].

Analysis of the atomic mass number 3 (HD) release in TEXTOR during the RF conditioning pulse revealed a noticeable rise in the $Q_{\mathrm{RR}}$ quantity at both, high and low $\mathrm{B}_{\mathrm{T}}$-fields (Fig.6). The $\mathrm{H}_{2}$-injection into He-plasmas made the conditioning more effective. At high magnetic field $\left(\mathrm{B}_{\mathrm{T}} \approx 2.3 \mathrm{~T}\right.$, presence of the fundamental ICR, $\left.\omega=\omega_{\mathrm{cH}+}\right)$, the observed effect may be attributed to (i) the improved plasma 
homogeneity through the MC process, (ii) the proton cyclotron acceleration at $\omega=\omega_{\mathrm{cH}}+$ and (iii) the hydrogen induced chemical erosion/isotope exchange. The noticeable conditioning effect at low $\mathrm{B}_{\mathrm{T}}(\approx 0.2 \mathrm{~T}$, regime of high IC harmonic $(\mathrm{HCH})$ operation, $\omega \approx 10 \omega_{\mathrm{cH}^{+}}$) was probably related to (i) the better plasma homogeneity and (ii) the chemical erosion [13]. Modeling of the power deposition profiles predicted a decrease of ion cyclotron absorption and increase of electron collisional absorption with decreasing the $\mathrm{B}_{\mathrm{T}}$ and may be considered as an indirect evidence of the favourable impact of the fundamental ICR on the ICWC output [13]. The conditioning effect was further improved by applying a small $\mathrm{B}_{\mathrm{V}}$-field in addition to $\mathrm{B}_{\mathrm{T}}\left(\mathrm{B}_{\mathrm{V}}<<\mathrm{B}_{\mathrm{T}}\right.$, Fig.6).

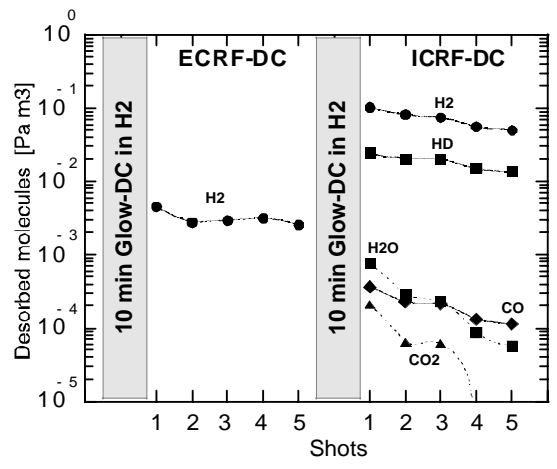

FIGURE 5. Comparison of desorption rates for selected gas species in a series of ECWC and ICWC discharges on TEXTOR $\left(\mathrm{B}_{\mathrm{T}}=2.0 \mathrm{~T}\right.$, $\mathrm{p}_{\mathrm{He}}=2.5 \times 10^{-2} \mathrm{~Pa}, \mathrm{P}_{\mathrm{ECWC}-\mathrm{G}} \approx 150 \mathrm{~kW}, f_{\mathrm{ECWC}}=110$ $\mathrm{GHz}, \mathrm{P}_{\text {ICWC-G }}=60 \mathrm{~kW}, f_{\mathrm{ICWC}}=32.5 \mathrm{MHz}[1,10]$.

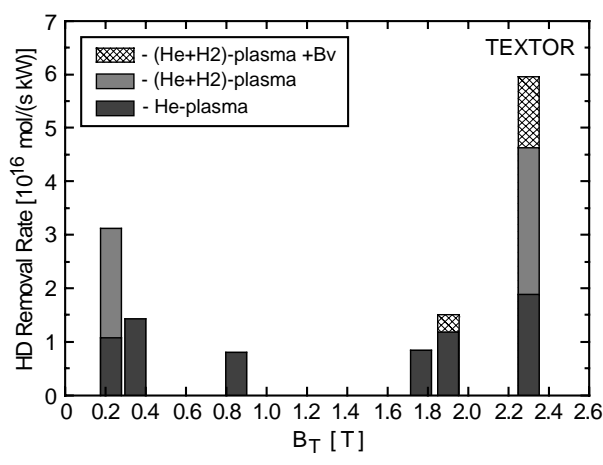

FIGURE 6. $\mathrm{B}_{\mathrm{T}} / \mathrm{B}_{\mathrm{V}}$-dependence of $\mathrm{HD}$ $(\mathrm{m}=3)$ removal rate in He-plasmas (normalized to $\mathrm{P}_{\mathrm{RF}-\mathrm{pl}}$ shown in Fig.3) and added up $\mathrm{H}_{2}$-puff and $\mathrm{B}_{\mathrm{v}}$-field contribution $\left(p_{\text {tot }} \approx(4-6) \times 10^{-2} \mathrm{~Pa}\right)[13]$.

\subsection{ICWC Extrapolation to ITER}

Modeling of the absorbed power in the ITER-size ICWC plasmas was performed for the MC scenario following the best results of the ICWC efficiency achieved in the present-day tokamaks. The TOMCAT code predicts that a more homogeneous power absorption by the electrons over the ITER vessel may be achieved with the MC scenario in $\left(\mathrm{He}+\mathrm{H}_{2}\right)$-plasmas at $\mathrm{B}_{\mathrm{T}}=3.6 \mathrm{~T}$ with two operational frequencies, $f_{1}=40 \mathrm{MHz}$ and $f_{2}=48 \mathrm{MHz}$ [6]. Performance of the $\mathrm{MC}$ scenario at half-field $\left(\mathrm{B}_{\mathrm{T}}=2.65 \mathrm{~T}\right)$ or at full field $\left(\mathrm{B}_{\mathrm{T}}=5.3 \mathrm{~T}\right)$ may result in less homogeneous ICWC discharge (Fig.7). However, plasma production with antennas generated RF power in a low $k_{\mathrm{z}}$ dominated spectrum looks beneficial: (i) FW is already propagating in low density plasmas; (ii) better antenna coupling is foreseen; (iii) larger fraction of the coupled RF power may be transported to the antenna distant conversion layers. To improve the RF plasma homogeneity, an application of the poloidal magnetic field $\left(B_{\mathrm{V}, \mathrm{R}}<<B_{\mathrm{T}}\right)$ and assistance with the on-axis ECRF ionization will probably be needed.

The 0-D plasma code [19] was used to simulate hydrogen/deuterium RF plasmas in ITER-size machine $\left(\bar{a}_{p l} \approx 2.4 \mathrm{~m}, R_{0}=6.2 \mathrm{~m}\right)$ in the presence of $B_{\mathrm{T}}=5.3 \mathrm{~T}$ in the pressure range $p \approx(2-8) \times 10^{-2} \mathrm{~Pa}$ for the averaged power per neutral (at room temperature) $\mathrm{P} / \mathrm{N}$ $\approx 70 \mathrm{~kW} /\left(\mathrm{Pa} \cdot \mathrm{m}^{3}\right)$. The code predicts that $\mathrm{RF}$ plasmas with density of $n_{\mathrm{e}} \approx$ $(1-5) \times 10^{17} \mathrm{~m}^{-3}$, temperature $T_{\mathrm{e}} \approx 1-2 \mathrm{eV}$ and ionization degree $\gamma_{T} \approx 0.05-0.10$ can be produced with the $\mathrm{RF}$ power coupled to the electrons in the range $\mathrm{P}_{\mathrm{RF}-\mathrm{pl} \text { (ITER) }}$ $\approx 0.3-1.3 \mathrm{MW}$ depending on the gas pressure (Fig.8). Assuming an "optimistic" antenna coupling efficiency $\eta \geq 50 \%$ at the "monopole"-phasing [24], this corresponds 
to a generator power around $\mathrm{P}_{\mathrm{RF}-\mathrm{G}}$ (ITER) $\approx 0.6-2.6 \mathrm{MW}$. The empirical direct extrapolation from the TEXTOR ICWC data (coupled power $\mathrm{P}_{\mathrm{RF}-\mathrm{pl} \text { Textor }} \approx 12 \mathrm{~kW}$, similar power density scaling and antenna coupling) gives a power of $\mathrm{P}_{\mathrm{RF}-\mathrm{pl} \text { (ITER) }}$ $\approx 0.8 \mathrm{MW}$ and $\mathrm{P}_{\mathrm{RF}-\mathrm{G}(\mathrm{ITER})} \approx 1.6 \mathrm{MW}$, respectively.

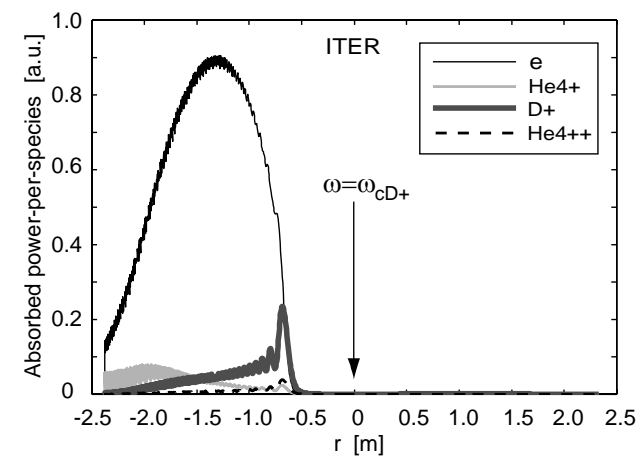

FIGURE 7. 1-D simulation of the RF power deposition profiles in the ITER-size plasma $\left(\mathrm{B}_{\mathrm{T}}=5.3 \mathrm{~T}, \quad f=40 \mathrm{MHz}, \quad k_{\mathrm{z}}=1.6 \mathrm{~m}^{-1}\right.$, $n_{\mathrm{e}}=3 \times 10^{17} \mathrm{~m}^{-3}$, plasma composition: $60 \% \mathrm{He}_{4}{ }^{1}$ $+30 \% \mathrm{D}_{2}{ }^{1}+5 \% \mathrm{He}_{4}{ }^{2}+2.5 \% \mathrm{H}_{1}{ }^{1}+2.5 \% \mathrm{C}_{12}{ }^{1}$.
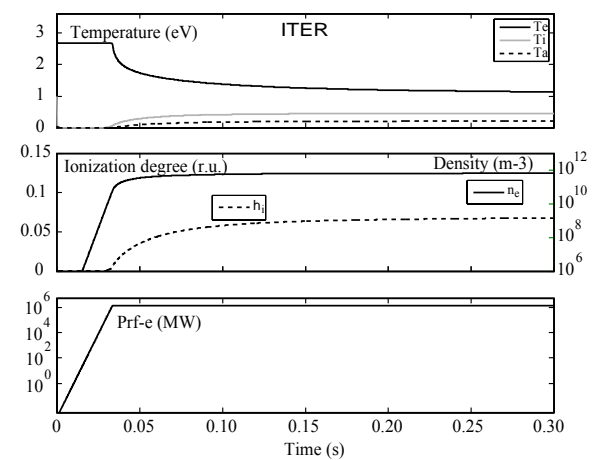

FIGURE 8. 0 -D simulation of the $\mathrm{H}_{2} / \mathrm{D}_{2}$ plasma production in ITER-size machine for averaged power per neutral: $\mathrm{P} / \mathrm{N} \approx$ $70 \mathrm{~kW} /\left(\mathrm{Pa} \cdot \mathrm{m}^{3}\right), \mathrm{p}_{\mathrm{H} 2}=8 \times 10^{-2} \mathrm{~Pa}, \mathrm{P}_{\mathrm{RF}-\mathrm{e}}=1.3 \mathrm{MW}$.

\section{ACKNOWLEDGMENTS}

This work, supported by the European Communities under the contract of Association EURATOM/Belgian state, was carried out within the framework of the European Fusion Development Agreement. The views and opinions expressed herein do not necessarily reflect those of the European Commission.

\section{REFERENCES}

1. A. Lyssoivan, et al., Problems of Atomic Science and Technology 1 (13) (2007) 30-34.

2. O.M. Shvets, et al., $4^{\text {th }}$ Int. Symp. on Heating in Toroidal Plasmas, Roma, 1984, ENEA, Vol.1 (1984) 513-528.

3. N.I. Nazarov, et al., Soviet J. Plasma Phys. 13 (1987) 871-873.

4. Lyssoivan A.I., et al., 22nd EPS Conf. on CFPP, Bournemouth 1995, Vol.19C, Part III, 341; 23rd EPS Conf. on CFPP, Kiev 1996, Vol.20C, Part II, 879; LPP-ERM/KMS Lab. Report 114 (1998).

5. E. Gauthier, et al., J. Nucl. Mater. 241-243 (1997) 553-558.

6. H.G. Esser, et al. J. Nucl. Mater. 241-243 (1997) 861-864.

7. E. de la Cal, E. Gauthier, PPCF 39 (1997) 1083.

8. R. Koch, et al., 16th IAEA Fusion Energy Conf., Montreal 1996, IAEA Vienna 1997, Vol. 1, 633; 26th EPS Conf. on CFPP, Maastricht 1999, ECA Vol.23J, 745-748.

9. J.Li, et al., Nucl. Fusion 39 (1999) 973-978.

10. E. Gauthier, et al., 28th EPS Conf. on CFPP, Madeira 2001, Paper P5.094.

11. R. Brakel, et al., J. Nucl. Mater. 290-293 (2001) 1160-1165.

12. E. de la Cal, E. Gauthier, PPCF 47 (2005) 197-218.

13. A. Lyssoivan, et al., J. Nucl. Mater. $337-339$ (2005) 456; 363-365 (2007) 1358; 390-391 (2009) 907.

14. N. Ashikawa, et al., Fusion Eng. Design 81 (2006) 2831-2836.

15. J.S.Hu, et al., J. Nucl. Mater. 376 (2008) 207-210.

16. H.L. Yang, et al., $22^{\text {nd }}$ IAEA Fusion Energy Conf., Geneva, 2008, Paper FT/P3-4.

17. ITER Team, ITER Design Change Request DCR-080 (2007).

18. D. Van Eester and R. Koch, PPCF 40 (1998) 1949-1975.

19. J. Buermans and T. Matthys, Diploma Thesis, ERM/KMS, Brussels 2006.

20. V.E. Moiseenko, et al., Problems of Atomic Science and Technology 6 (12) (2006) 62-64.

21. M.D. Carter, et al., Nucl. Fusion 30 (1990) 723-730.

22. A. Lyssoivan, et al., Nucl. Fusion 32 (1992) 1361-1372.

23. M.K. Paul, et al., this conference.

24. T. Wauters, et al., this conference.

25. J.G. Kwak (private communication).

26. P.C. Stangeby and G.M. McCracken, Nuclear Fusion 30 (1990) 1225-1379.

27. J. Winter, Plasma Phys. Control. Fusion 38 (1996) 1503-1542.

28. K. Itami, et al., J. Nucl. Mater. (2009), doi:10.1016/j.jnucmat.2009.01.254. 